\title{
CAUSES OF NON-TRACHOMATOUS OPHTHALMIA IN EGYPT
}

\author{
BY \\ A. F. MacCallan, M.D., \\ DIRECTOR OF OPHTHALMIC HOSPITALS, CAIRO, EGYPT.
}

IN a communication to the Ophthalmological Society of the United Kingdom, Session 1917-1918, I reported certain observations on the relation between the varieties of conjunctivitis and the average climatic temperature. Similar observations have been regularly made and published in the Annual Reports of the Egyptian Ophthalmic Hospitals since the year 1912.

We have found that the number of new patients who present themselves for treatment is very much greater in the summer than in the winter. This may be due to some extent to the shorter daýs of winter giving less time for those who come from a distance to go to and come from the hospital, and to the condition of the roads during rainy weather preventing travelling, but is mainly due to the increased amount of communicable eye disease, that is acute conjunctivitis, during the summer months. We have previously shown that neither atmospheric humidity nor variations in the level of the Nile bear any relation to this increased incidence of conjunctivitis. The following table shows the number of patients seeking treatment in each month of the year.

Table I.-New patients treated per month

$\begin{array}{llllllll}\text { January } & \ldots & \ldots & \ldots & \ldots & \ldots & \ldots & 3,954 \\ \text { February } & \ldots & \ldots & \ldots & \ldots & \ldots & \ldots & 4,648 \\ \text { March } & \ldots & \ldots & \ldots & \ldots & \ldots & \ldots & 6,511 \\ \text { April } & \ldots & \ldots & \ldots & \ldots & \ldots & \ldots & 7,288 \\ \text { May } & \ldots & \ldots & \ldots & \ldots & \ldots & \ldots & 7,583 \\ \text { June } & \ldots & \ldots & \ldots & \ldots & \ldots & \ldots & 7,503 \\ \text { July } & \ldots & \ldots & \ldots & \ldots & \ldots & \ldots & 8,181 \\ \text { August } & \ldots & \ldots & \ldots & \ldots & \ldots & \ldots & 9,980 \\ \text { September } & \ldots & \ldots & \ldots & \ldots & \ldots & \ldots & 7,494 \\ \text { October } & \ldots & \ldots & \ldots & \ldots & \ldots & \ldots & 7,782 \\ \text { November } & \ldots & \ldots & \ldots & \ldots & \ldots & \ldots & 7,115 \\ \text { December } & \ldots & \ldots & \ldots & \ldots & \ldots & \ldots & 4,277 \\ & & & & & \text { Total } & \ldots & 82,316\end{array}$

Table II exhibits the relation between the average atmospheric temperature and the number of new patients treated per month. The average temperature is obtained by taking two places in Lower Egypt, Qurashia and Zagazig, and two places in Upper Egypt, 
Beni Suef and Assiut, and obtaining an average figure from the mean temperature at each place on the 1st and 16th of each month. This average temperature is supplied by the kindness of the Director General of the Meteorological Department.

Table II.-Temperature and number of patients treated

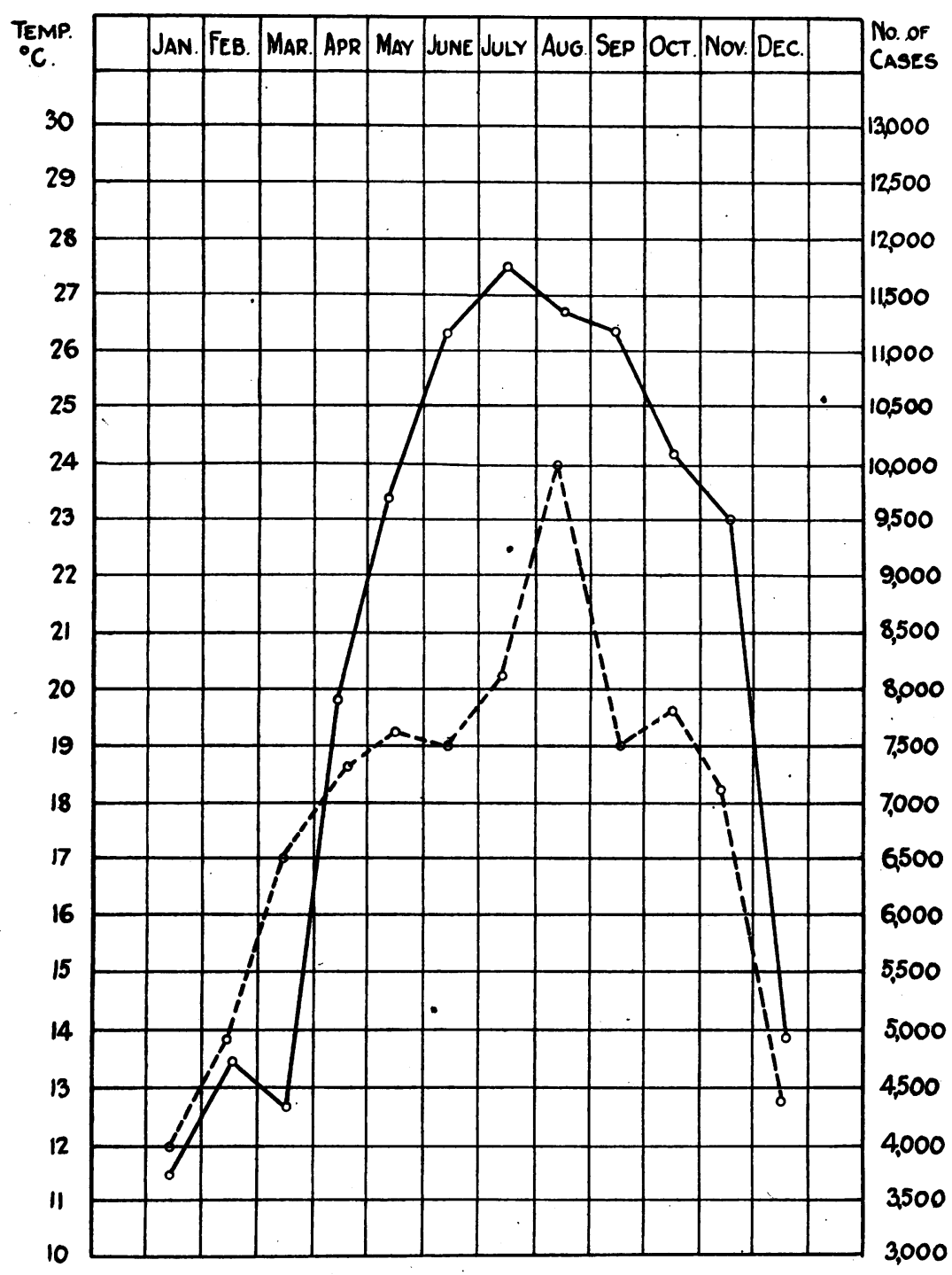

Average temperature in degrees centigrade.

New patients treated per month. 
While in December and January the new patients are about 4,000 or 5,000 per month, in August they number 10,000 . The increase begins in the spring of each year about the same time as the rise in the average temperature; this was more marked in our records for 1917 than in the accompanying curve for 1918 .

It is seen that the general trend of the two curves is very similar and it is impossible to resist the impression that there is a definite relation between rises and falls of temperature and increased desire for ophthalmic treatment.

Table III shows that 11,500 microscopical examinations with a $1 / 12$ oil immersion lens showed the presence of one or other of the causative organisms of acute conjunctivitis out of a total of 13,500 examinations made. The number per month varying from about 300 in January to about 1,600 in October.

Table III._Organisms found during 1918

\begin{tabular}{|c|c|c|c|c|c|c|c|c|c|c|c|c|c|c|}
\hline Organisms. & & 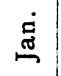 & 造 & $\underset{\Sigma}{\tilde{c}}$ & 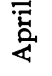 & 空 & $\stackrel{\Xi}{\Xi}$ & $\stackrel{\infty}{\Xi}$ & $\stackrel{\infty}{\vec{z}}$ & $\begin{array}{l}\text { 苔 } \\
\text { ஸे }\end{array}$ & ث̈ं & 完 & $\begin{array}{l}\dot{\Phi} \\
\stackrel{\Phi}{\circ}\end{array}$ & Total \\
\hline Gonococcus & ... & .66 & 61 & 63 & $10^{\circ}$ & 416 & 410 & 604 & 669 & 794 & 1003 & 825 & 270) & 5282 \\
\hline Weeks & $\ldots$ & 51 & 70 & 198 & 390 & 503 & 377 & 263 & 352 & 284 & 342 & 269 & 120 & 3219 \\
\hline $\begin{array}{l}\text { Morax or Diplo- } \\
\text { bacill }\end{array}$ & & 181 & 225 & 344 & 185 & 253 & 141 & 184 & 207 & 198 & 165 & 118 & 74 & 2275 \\
\hline Pneumococcus & $\cdots$ & 17 & 12 & 23 & 35 & 27 & 28 & 29 & 23 & 48 & 43 & 63 & 30 & 378 \\
\hline Xerosis & ... & 11 & 3 & 8 & 11 & 21 & 29 & 18 & 20 & 17. & 12 & 14 & 15 & 179 \\
\hline Staphylococcus & ... & 1 & 1 & 7 & 3 & 11 & 5 & 8 & 8 & 6 & 6 & 7 & 1 & 64 \\
\hline Micrococcus & ... & - & - & - & 1 & 4 & - & 一 & 3 & - & - & - & - & 8 \\
\hline Streptococcus & ... & 一 & - & 3 & 3 & 1 & 1 & - & - & 3 & - & 1 & 3 & 15 \\
\hline Other organisms & ... & 7 & 2 & 17 & 7 & 12 & 6 & 15 & -18 & 7 & 9 & 2 & 1 & 93 \\
\hline Total & $\ldots$ & 334 & 374 & 663 & 736 & 1248 & 997 & 121 & 1290 & 1357 & 1580 & 1299 & 514 & 11513 \\
\hline Negative $\quad .$. & $\cdots$ & 68 & 79 & 139 & 169 & 259 & 189 & 194 & 227 & 212 & 209 & 225 & 101 & 2071 \\
\hline Grand total & $\cdots$ & 402 & 453 & 802 & 905 & 507 & 1186 & 315 & 1517 & 1569 & 1789 & 1524 & 615 & 13584 \\
\hline
\end{tabular}

As practically all cases of acute conjunctivitis are examined microscopically, the number of microscopical examinations bears a pretty fair relation to the amount of acute conjunctivitis. 


\section{Causes of Non-Trachomatous Ophthalmia in Egypt 501}

Table IV exhibits the monthly percentage of organisms found in the various months of the year, the curve for which is seen to rise shortly subsequent to the rise of temperature and favours the conclusion that the main increase in the number. of patients is due to the increased prevalence of acute conjunctivitis.

Table IV.-Temperature and positive examinations

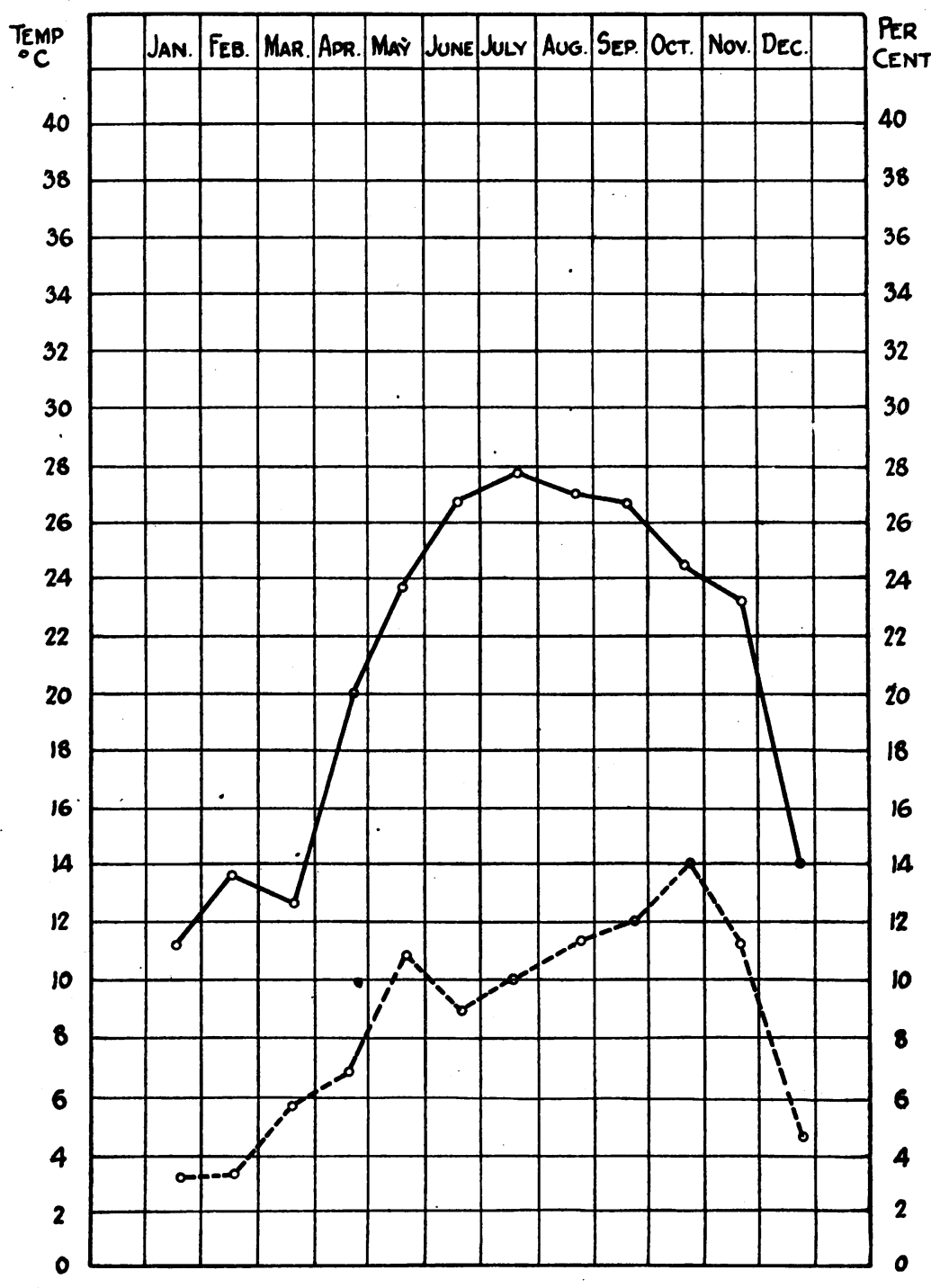

Average temperature in degrees centigrade.

Percentage monthly of positive examinations on total of all micro-organisms found during 1918. 
Table $\mathrm{V}$ shows the relations of the gonococcus to the temperature, while Table VI does the same for the Weeks bacillus, and Table VII for the Morax bacillus.

Table $\cdot$ V.-Temperature and gonococcus

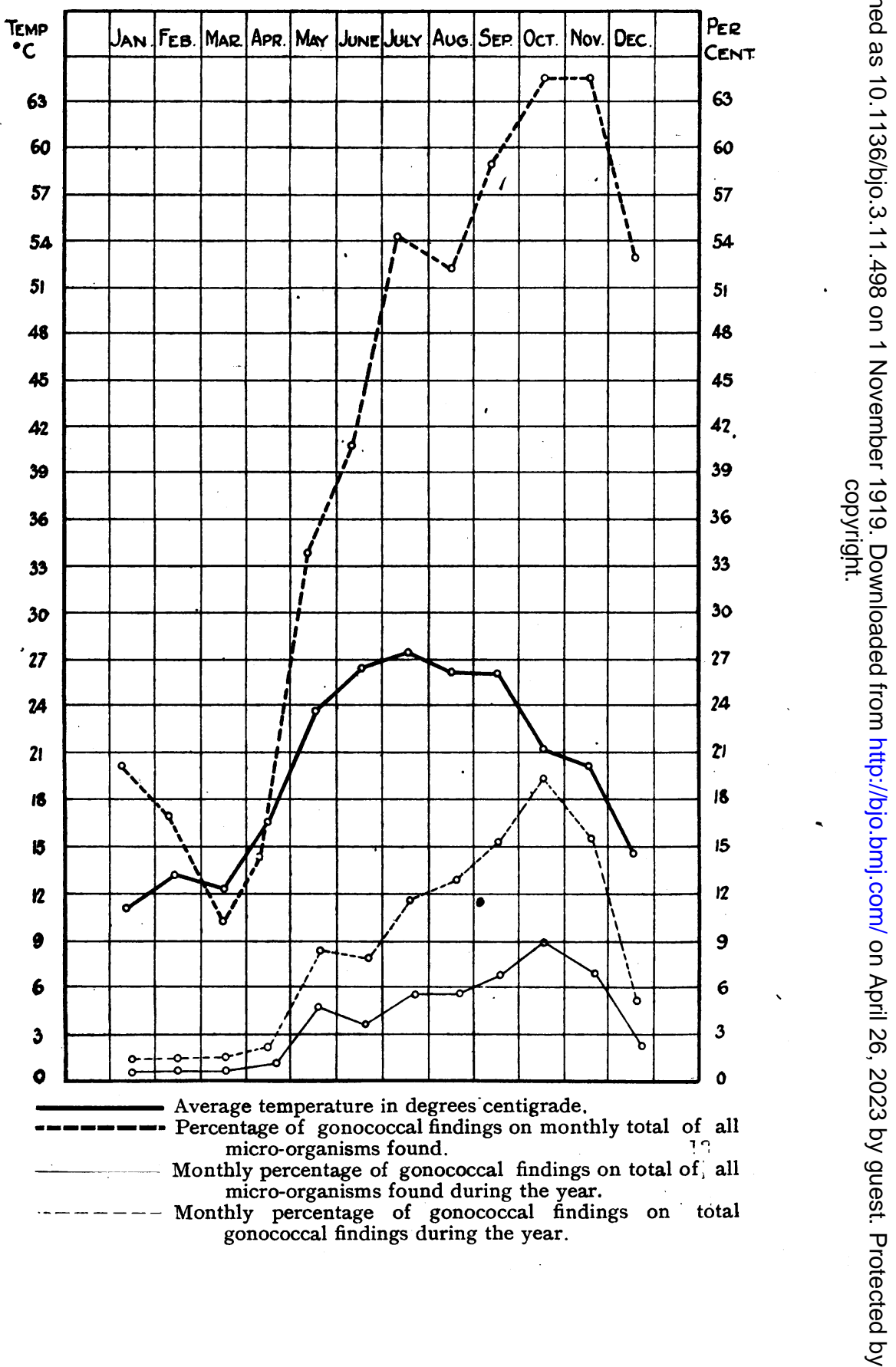


Causes of Non-Trachomatous Ophthalmia in Egypt 503

Table VI.-Temperature and Weeks Bacillus



Average temperature in degrees centigrade.

Percentage of Weeks bacillus finding on monthly totals of micro-organisms.

Percentage of Weeks bacillus findings on total of all microorganisms found during the year.

Monthly percentage of Weeks bacillus on total Weeks bacillus finding during the year. 
Table VII.-Temperature and Morax's Bacillus

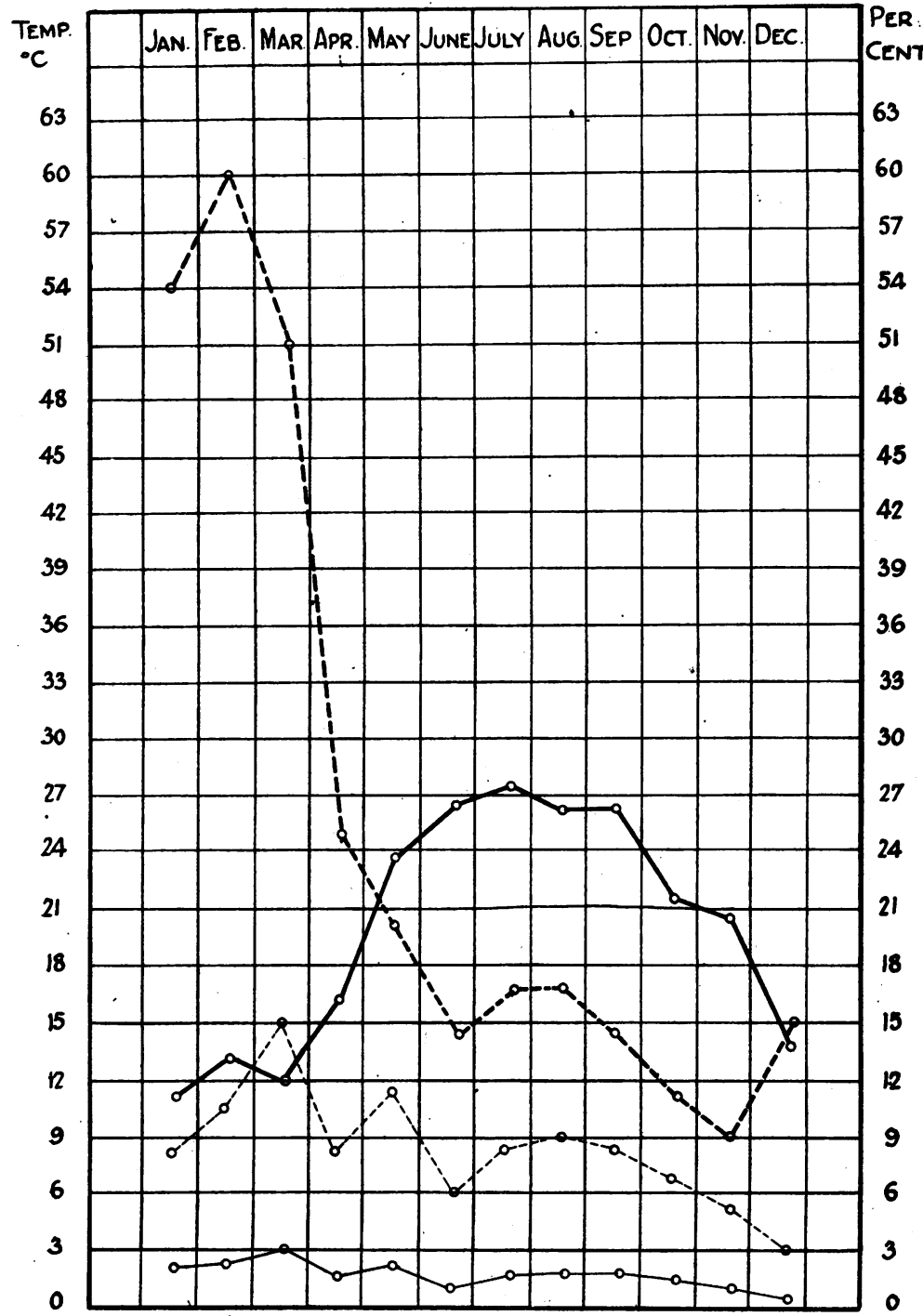

Average temperature in degrees centigrade.

Percentage of Morax bacillus finding on monthly totals of micro-organisms found.

Percentage of Morax bacillus on total of all microorganisms found during the year.

Monthly percentage of Morax bacillus on total Morax bacillus findings during the year. 
In each case $(a)$ table exhibits the average temperature. The (b) table exhibits the monthly percentage of a particular organism on the monthly total of all micro-organisms found; that is to say, it shows what frequency the particular organism exhibits as compared with the total number of micro-organisms found. The (c) table exhibits the monthly percentage of a particular organism on the total of all micro-organisms found during the year; that is to say, it shows the seasonal variation as compared with all other microorganisms. The $(d)$ table shows in another form to that exhibited in the $(e)$ table the varying seasonal incidence of the particular organism.

The gonococcus is seen to be the main cause of the increase of acute cases of conjunctivitis (Table V), and the increases appear subsequent to the rise of temperature, although the upward trend of the gonococcal curve continues disproportionately long as compared with that of the temperature; also the maximum amount of gonococcal conjunctivitis is found in October, while the maximum temperature is reached in July.

The conjunctivitis due to the Weeks' bacillus certainly increases with the spring rise in the temperature, but its maximum incidence is found in April or May and not in October as we have seen is the case with the gonococcus.

Conjunctivitis due to the Morax bacillus does not vary so much during the year in its incidence as the above-mentioned organisms. It is, however, somewhat more prevalent in the early part of the year, and comparatively to the other organisms, as seen in Table VII, is much more frequent at this time.

The conclusions arrived at from these curves are not materially different from those published in my previous reports.

\title{
EYE SYMPTOMS AS THE ONLY INDICATION OF FRACTURED BASE OF THE SKULL
}

\author{
BY \\ Sydney STEPhenson, \\ LONDON.
}

EVERY ophthalmic surgeon has met with patients in whom eye symptoms formed part and parcel of those which, taken as a whole, indicate a fractured base of the skull. The object of the present communication is to draw attention to a group of cases in which the injury to the skull is shown exclusively or chiefly by the appearances of the eyes in conjunction with the history. My meaning may be rendered clearer by a perusal of the following four cases, from which care has been taken to exclude any direct injury of the eyes 